\title{
UMA COLEÇÃO DIDÁTICA PARA O ENSINO DE LATIM EM ANÁLISE
}

\begin{abstract}
Luciana Maria Almeida de Freitas é docente da Faculdade de Educação da UFF. Atua no Programa de Pós-Graduação em Estudos de Linguagem, na Linha de Pesquisa Estudos aplicados de linguagem, e na Graduação em Letras, lecionando disciplinas de Prática de Ensino. É doutora em Letras Neolatinas pela UFRJ e mestra em Lingüística pela UERJ. Lidera o Grupo de Pesquisa Práticas de linguagem, trabalho e formação docente (UFF) e participa como pesquisadora dos grupos Práticas de Linguagem e discursividade (PraLinS-UERJ) e Atelier (PUC-SP). Integra o GT da Anpoll Linguagem, Enunciação e Trabalho.

E-mail: lucianafreitas@uol.com.br

Thiago da Silva Pinheiro é graduando em Letras (Português-Latim) na UFF. Foi bolsista de Iniciação à Docência no Colégio Universitário Geraldo Reis (COLUNI-UFF) e, atualmente, pesquisa sobre Avaliação de atividades escritas em perspectiva dialógica e sobre Análise de livros didáticos para o ensino de latim, ambas relacionadas a suas atividades de monitoria da disciplina Pesquisa e Prática de Ensino I e II na Faculdade de Educação da UFF. Integra o Grupo de Pesquisa Práticas de linguagem, trabalho e formação docente (UFF).

E-mail: iacobus.pinus@yahoo.com.br
\end{abstract}

\section{Resumo}

O trabalho que propomos visa a apresentar uma análise da coleção didática LINGUA LATINA PER SE ILLUSTRATA, escrita por Hans Ørberg na década de 1990, a partir de pesquisas sobre o ensino de línguas.

\begin{abstract}
Resumen
El trabajo que proponemos busca presentar un análisis de la colección didáctica LINGUA LATINA PER SE ILLUSTRATA, escrita por Hans Ørberg en la década de 1990, a partir de investigaciones sobre la enseñanza de lenguas.
\end{abstract}

\section{Introdução}

Neste trabalho, desejamos refletir sobre uma coleção de livros didáticos para ensino de latim. Esta análise tem por antecedentes os questionamentos que fazemos desde o início dos estudos clássicos e que, de certa forma, inquietam-me até hoje. Perguntas como "por que ensinar uma língua clássica - latim, grego - nos dias de hoje?" e "se o latim não é uma língua ensinada nas escolas e o alunado é bastante específico, há algum material didático (livro didático ou coleção) de apoio aos docentes/discentes no percurso dos estudos?" são norteadoras dessa pesquisa que desenvolvemos.

Outras dúvidas surgiram: os materiais/coleções/livros didáticos a que tive acesso atendem às expectativas dos sujeitos envolvidos no processo de ensino-aprendizagem? Buscando discutir tais questões, depois de analisar alguns desses materiais em outros trabalhos, apresentamos reflexões sobre um tomo pertencente a uma coleção bastante vasta e que continua crescendo. A opção pela coleção, intitulada LINGUA LATINA PER SE ILLUSTRATA, se deve ao fato de termos observado que se trata de um material que busca diferenciar-se dos demais e apresenta propostas que vão além da abordagem gramáticatradução.

Para analisá-lo, buscaremos o arcabouço teórico da concepção dialógica de linguagem (BAKHTIN, 2003; VOLOSHINOV, 2009), da Análise do Discurso de base enunciativa (MAINGUENEAU, 1997; 2002) e de pesquisas sobre o ensino de língua

Revista Escrita

Rua Marquês de São Vicente, 225 Gávea/RJ CEP 22453-900 Brasil

Ano 2012. Número 15. ISSN 1679-6888.

escrita@puc-rio.br 
materna (ROJO, 2005; 2008; GERALDI, 2006; MARCUSCHI, 1996) e estrangeira (MOITA LOPES, 1996).

Esperamos suscitar novos estudos no campo do ensino de línguas clássicas, e que, exarantibus litteris $^{l}$, possamos contribuir melhor para a formação de latinistas professores e alunos.

\section{Latim: uma língua morta?}

Tratar a língua sob a ótica de que é um sistema imóvel, sem vida, sem possibilidades de movimento é ignorar seu efetivo funcionamento. E aí afirmamos nossa posição para o ensino de letras clássicas: não concordamos com o tratamento de "língua morta" dado ao latim e ao grego antigo, por exemplo. Palavras como as de Coutinho (1970, p. 27) nos fazem essa referência explícita:

44. Quanto ao uso, classificam-se as línguas em vivas, mortas e extintas. (...)

46. MORTAS, as que já não são faladas, mas deixaram documentos escritos, como o latim e o grego literários.

Esta análise não buscou essa perspectiva de língua. Não obstante sua inexistência em alguma comunidade como era no vasto Império Antigo - o latim, como língua que, como qualquer outra, se portou como sistema vivo -, desenvolveu-se. Ele não deixou de ser usado. Inclusive é a língua oficial da Igreja até os dias de hoje, embora não seja L1 de nenhum grupo social. Os registros literários que temos nos oferecem a certeza de um estado, tão somente. E é um sem-número desses textos. Afirma Monteil (2003, p. 39):

Como lengua escrita, el latín no ha dejado de emplearse, hasta en fechas en ocasiones cercanas a nuestros días, en determinados usos literarios, jurídicos, diplomáticos o litúrgicos. Como lengua hablada, es delicado determinar la fecha en la que el latín ha dejado de usarse.

Há escolas, especialmente na Europa, onde é regra de uso o falar em língua latina ou língua grega antiga ${ }^{2}$. Esse é mais um indício de que tratar a língua como morta, e não um continuum do sistema que gerou o espanhol, o francês, o italiano e o português, por exemplo, é um equívoco. É sobre esse desenvolvimento do sistema lingüístico que fala Williams (1973, introdução):

O latim como língua viva estava sujeito a constantes modificações. Enquanto a língua das classes cultivadas (o latim clássico) se tornava cada vez mais uniforme sob a influência estabilizadora da cultura e do aprendizado, a língua do povo (o latim vulgar)

\footnotetext{
${ }^{1}$ Em uma tradução livre, "buscar as preciosidades nas letras".

${ }^{2}$ A própria Academia que edita os livros oferece um curso de fundamentos Humanistas talhado sob esse viés. Chama-se Accademia Vivarium Novum.

Revista Escrita

Rua Marquês de São Vicente, 225 Gávea/RJ CEP 22453-900 Brasil

Ano 2012. Número 15. ISSN 1679-6888.

escrita@puc-rio.br
} 
se tornava cada vez mais diversificada na medida em que se disseminava como a expansão do vasto Império Romano. O latim clássico se tornava uma língua morta, enquanto o latim vulgar se desenvolvia nas chamadas línguas neolatinas ou românicas.

Como toda língua, há variações no sistema devido aos substratos, superestratos e adstratos daquela comunidade linguística. O latim se transformar de clássico - registrese, textos literários, até porque, a língua falada, obviamente, não era da forma que temos registrada hoje em dia - a vulgar não significa a morte de um sistema. Significa sim, uma mudança significativa. O caminho LATIM CLÁSSICO $\rightarrow$ LATIM VULGAR $\rightarrow$ NEOLATINAS é um percurso nada mais que evolutivo de um sistema. Eles foram momentos do continuum que resultou em línguas naturais em uso nos dias atuais e o que fazemos é estudar um desses momentos.

\section{Gêneros Discursivos e o Ensino de LC}

Bakhtin (2003, p.265) afirma que "a língua passa a integrar a vida através de enunciados concretos (que a realizam); é igualmente através de enunciados concretos que a vida entra na língua". E ainda que "cada enunciado particular é individual, mas cada campo de utilização da língua elabora seus tipos relativamente estáveis de enunciados, os quais denominamos gêneros do discurso" (BAKHTIN, 2003, p. 262, grifos do autor). Dessa forma, os conceitos de enunciado concreto e de gênero discursivo estabelecem uma iniludível relação entre a língua e o mundo social, pois nenhum enunciado pode ser analisado, nessa perspectiva, como uma abstração, tendo em vista que está integrado constitutivamente a uma situação de enunciação, com seu lugar, sua época, seus interlocutores. Assim, continua o russo (2003, p. 282):

Os enunciados e seus tipos, isto é, os gêneros discursivos, são correias de transmissão entre a história da sociedade e a história da linguagem. Nenhum fenômeno novo (fonético, léxico, gramatical) pode integrar o sistema da língua sem ter percorrido um complexo e longo caminho de experimentação e elaboração de gêneros e estilos.

Por fim, levantamos uma questão fundamental acerca da concepção de gramática, tendo em vista o tratamento a ela concedido no livro analisado. Para Bakhtin, (2003), os gêneros se constituem de três elementos relacionados entre si: estilo, tema e construção composicional. Desses três elementos, interessa-nos aqui o estilo, que se relaciona com a "seleção dos recursos lexicais, fraseológicos e gramaticais da língua" utilizados na composição do gênero. Diz ele (BAKHTIN, 2003, p. 269):

A gramática (e o léxico) se distingue substancialmente da estilística (alguns chegam até a colocá-la em oposição à estilística), mas ao mesmo tempo nenhum estudo de gramática (já nem falo de gramática normativa) pode dispensar observações e incursões estilísticas. (...) A própria escolha de uma determinada forma gramatical pelo falante é um ato estilístico.

Nos estudos relativos ao ensino de línguas modernas, tanto materna quanto

Revista Escrita

Rua Marquês de São Vicente, 225 Gávea/RJ CEP 22453-900 Brasil

Ano 2012. Número 15. ISSN 1679-6888.

escrita@puc-rio.br 
estrangeiras, tem-se recorrido, com bastante frequência, ao conceito bakhtiniano de gênero discursivo. Os Parâmetros Curriculares Nacionais (BRASIL/SEF, 1998) preveem como eixo do ensino de línguas - tanto materna quanto estrangeira moderna o texto (escolhido de acordo com os temas transversais) e, no caso específico do português, propõem que o gênero discursivo seja o conceito que fundamenta as práticas didáticas. No entanto, vemos um apagamento dessa noção no ensino das línguas clássicas, que nos parece permanecer aferrado, segundo os exemplos que observamos neste trabalho, a uma concepção que tem como eixo a gramática, seja a normativa, seja a estrutural.

Outro fator importante a salientar é que o ensino por gêneros está no meio escolar há séculos. O trivium, conforme explica Rojo (2008, p. 79) conviveu com a língua portuguesa e seu ensino a partir de 1838; esta de maneira quase instrumental em relação àquela. A implantação da língua vernácula no ambiente escolar feita pelo Colégio Pedro II tinha por objetivo facilitar o estudo do trivium que se exercia em latim. Em uma citação de Razzini, Rojo (2008, p. 79) expõe:

O ensino da língua e da literatura portuguesa sempre se pautou pelo ensino das línguas clássicas, sobretudo o latim. A gramática nacional era estudada a partir das categorias gramaticais da língua latina e explicada como sua transformação, enquanto a literatura nacional era apresentada segundo os critérios fixos da retórica e da poética clássicas, dividida por gêneros. (grifo do autor).

Cabe, então, ressaltar dois aspectos nessa citação: o primeiro, como defendemos acima, que a língua materna é explicada como uma transformação do latim, não como vinda de uma língua morta. Não é adequado, portanto, a terminologia "língua morta" utilizada em larga escala para designar uma língua que sofreu transformações ao longo de muitos séculos e se transformou em patrimônio cultural de diversos países, em formas diferentes. Em segundo lugar, existe não apenas uma antiga tradição, mas uma forte tendência, principalmente nos últimos 30 anos, a dar centralidade ao conceito de gênero discursivo no ensino de línguas. Dessa forma, uma abertura das línguas clássicas a tal noção seria uma maneira de reverter o fluxo contrário da antiguidade que seguiram.

\section{A coleção em pauta: apresentação e análise}

O primeiro volume - curso básico - da coleção de livros de H. Ørberg, editada pela Accademia Vivarium Novum - LINGUA LATINA PER SE ILLUSTRATA - FAMILIA ROMANA (doravante LLPSI) -, nos anos 90 do século XX e atualizada até os dias de hoje, publicado originalmente na Dinamarca, é o nosso material analisado.

Além de dois livros do aluno que a integram, a coleção conta, ainda, com uma série de suplementos. São eles:

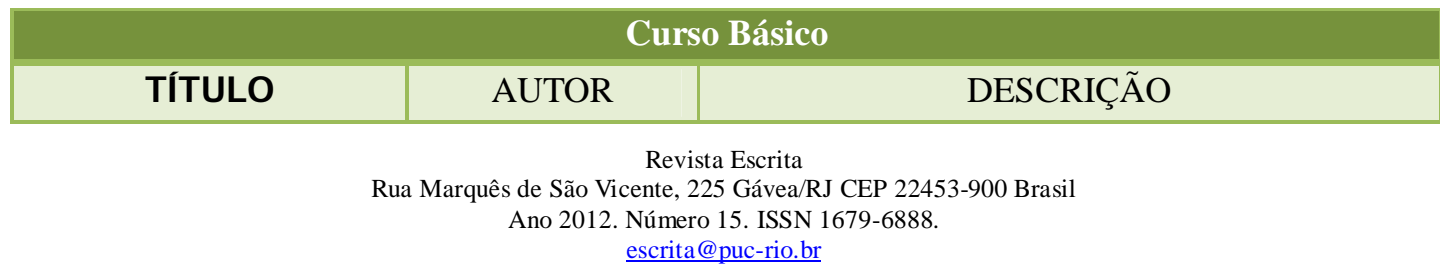




\begin{tabular}{|c|c|c|}
\hline Amphitryō & Hans H. Ørberg & $\begin{array}{c}\text { Uma peça de Plauto adaptada aos moldes das } \\
\text { Edições LLPSI }\end{array}$ \\
\hline Colloquia persōnārum & Hans H. Ørberg & $\begin{array}{l}\text { Diálogos para serem encenados pelos alunos. } \\
\text { Cada diálogo tem o vocabulário pertinente ao } \\
\text { capítulo que o numera. Sem notas e margens; } \\
\text { somente o texto. }\end{array}$ \\
\hline $\begin{array}{c}\text { Commentārīi } \\
\text { dē bellō Gallicōo }\end{array}$ & Hans H. Ørberg & $\begin{array}{l}\text { Um dos Livros de César adaptado aos moldes } \\
\text { das Edições LLPSI }\end{array}$ \\
\hline $\begin{array}{c}\text { Enchīridion } \\
\text { discipulōrum I } \\
\text { (cap. I-XXXV) }\end{array}$ & Hans H. Ørberg & $\begin{array}{l}\text { Conteúdo gramatical do LLPSI - Familia } \\
\text { Romana. Aqui o aluno encontra um texto para } \\
\text { cada capítulo como se o professor estivesse } \\
\text { explicando os tópicos gramaticais e filológicos } \\
\text { do texto. Trata de todos os tópicos que aparecem } \\
\text { em determinado capítulo. }\end{array}$ \\
\hline $\begin{array}{l}\text { Epitomē historiae } \\
\text { sacrae }\end{array}$ & Roberto Carfagni & $\begin{array}{c}\text { Reunião de diversas histórias sacras, com } \\
\text { exercícios. }\end{array}$ \\
\hline $\begin{array}{c}\text { Exercitia Latīna I } \\
\quad(\text { cap. } I-X X X V)\end{array}$ & Hans H. Ørberg & $\begin{array}{c}\text { Exercícios para LLPSI - Pars I. Exercícios de } \\
\text { copiação e gramática. }\end{array}$ \\
\hline Fābulae Syrae & Luigi Miraglia & $\begin{array}{c}\text { Caderno de fábulas ao molde das Edições } \\
\text { LLPSI. }\end{array}$ \\
\hline Familia Rōmāna & Hans H. Ørberg & $\begin{array}{l}\text { Livro didático que analisamos. Componente } \\
\text { principal do curso básico. }\end{array}$ \\
\hline $\begin{array}{l}\text { Grammatica di } \\
\text { consultazione }\end{array}$ & Hans H. Ørberg & $\begin{array}{l}\text { Compêndio gramatical com a sintaxe, } \\
\text { morfologia e fonética latinas. }\end{array}$ \\
\hline La via degli umanisti & $\begin{array}{c}\text { Documentario } \\
\text { (gratuito per } i \\
\text { docenti) }\end{array}$ & $\begin{array}{l}\text { Um guia didático para o professor que ilustra } \\
\text { aulas de latim com a coleção. }\end{array}$ \\
\hline Latīnēe discōo & $\begin{array}{l}\text { Hans H. Ørberg, } \\
\text { Luigi Miraglia e } \\
\text { Tommaso F. } \\
\text { Bórri }\end{array}$ & $\begin{array}{c}\text { Contém: } \\
\text { Enchīridion discipulōrum I, Colloquia } \\
\text { persōnārum, Exercitia Latīna I e Grammatica di } \\
\text { consultazione }\end{array}$ \\
\hline Novā viā Latīnēe docēō & Luigi Miraglia & $\begin{array}{l}\text { Guia para o professor de latim, com os } \\
\text { procedimentos ditos adequados para o ensino, } \\
\text { utilizando especialmente o LLPSI (como um } \\
\text { manual de instruções) e sugestões de exercícios } \\
\text { diversificados. Distribuído gratuitamente para os } \\
\text { docentes. Os fundamentos poderiam ser } \\
\text { aplicados a qualquer material didático. }\end{array}$ \\
\hline $\begin{array}{l}\text { Quaderno d'esercizi I } \\
\text { (cap. I-XIX) }\end{array}$ & $\begin{array}{c}\text { P. Coosemans, } \\
\text { H. Janssens, } \\
\text { P. Maes, } \\
\text { R. Vandessel, } \\
\text { A. Vangilbergen }\end{array}$ & $\begin{array}{l}\text { Caderno de exercícios com atividades de } \\
\text { copiação e composição textual. }\end{array}$ \\
\hline $\begin{array}{l}\text { Quaderno d'esercizi II } \\
\text { (cap. } X X-X X X I V)\end{array}$ & $\begin{array}{l}\text { P. Coosemans, } \\
\text { H. Janssens, }\end{array}$ & $\begin{array}{l}\text { Caderno de exercícios com atividades de } \\
\text { copiação e composição textual. }\end{array}$ \\
\hline
\end{tabular}

Revista Escrita

Rua Marquês de São Vicente, 225 Gávea/RJ CEP 22453-900 Brasil

Ano 2012. Número 15. ISSN 1679-6888.

escrita@puc-rio.br 


\begin{tabular}{|c|c|c|}
\hline & $\begin{array}{c}\text { P. Maes, } \\
\text { R. Vandessel, } \\
\text { A. Vangilbergen }\end{array}$ & \\
\hline Sermōnes Rōmāni & Hans H. Ørberg & $\begin{array}{c}\text { Volume que contém uma seleta de textos para } \\
\text { primeiras leituras, juntamente com o LLPSI - } \\
\text { Pars I. }\end{array}$ \\
\hline Vîta mōrēsque & Luigi Miraglia & $\begin{array}{c}\text { Descrição da sociedade romana Antiga, para ser } \\
\text { usada juntamente com o LLPSI. }\end{array}$ \\
\hline
\end{tabular}

O livro que é o fundamento do curso básico se estrutura de modo semelhante em quase todos os capítulos. Na essência de cada um há uma narrativa e/ou uma descrição da situação de uma família romana. Em suas estruturas, o texto é bastante repetitivo (vide Figura 1).

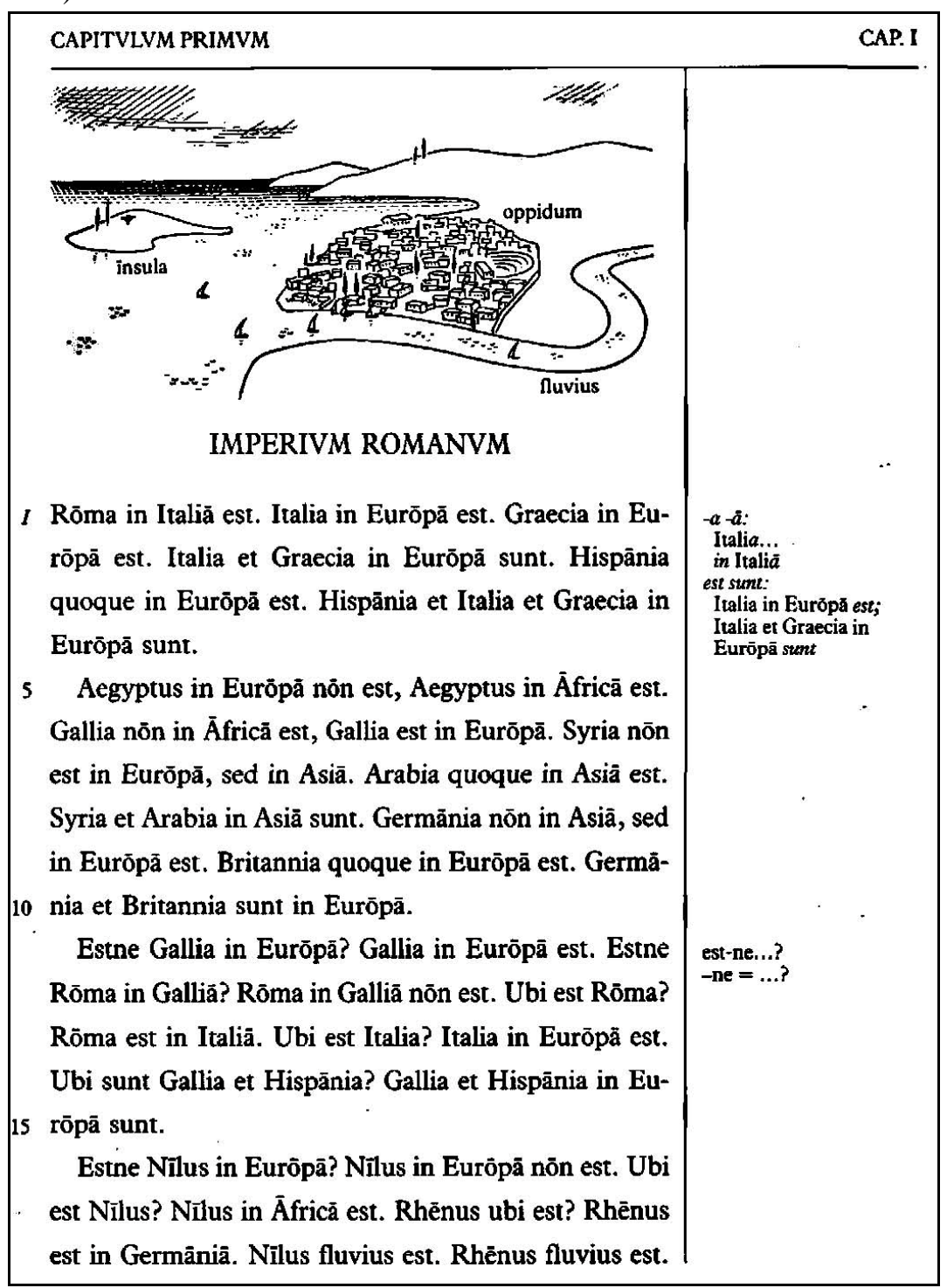

Figura 1- Página do primeiro capítulo. Note o detalhe da margem onde se explicita o conteúdo gramatical (Ørberg, 1991, p.7).

Revista Escrita

Rua Marquês de São Vicente, 225 Gávea/RJ CEP 22453-900 Brasil

Ano 2012. Número 15. ISSN 1679-6888.

escrita@puc-rio.br 
No caso da FAMILIA ROMANA normalmente acontecem diversas repetições, de forma muito visível nas primeiras lições. Com o desenvolver dos capítulos, a essa repetição das estruturas fica mais diluída, mas continua pertencendo às características da coleção. O mesmo acontece com vocábulos. A repetição dá indícios de que a concepção de língua que subjaz à coleção é a estruturalista.

Os textos que compõem cada capítulo são criados para fins didáticos. Há, no entanto, interpolações de textos clássicos já no curso básico. No FAMILIA ROMANA está incluída, nos capítulos finais, uma série de excertos, começando por trechos bíblicos textos de fácil compreensão devido a uma estrutura bastante próxima da fala ${ }^{3}-$, trechos de narrativas, citações de poetas e parte de uma gramática antiga na íntegra compondo integralmente um capítulo.

Há dois conjuntos de volumes de exercícios: um primeiro, que se compõe de exercícios com preocupações formais da língua (como funcionam determinadas construções da língua, por exemplo), e um segundo, que possui algumas atividades, além dessas citadas, de produção textual. Há, também, um livro com o conteúdo gramatical aprofundado segundo os moldes de gramáticas e outro que contém toda a explicação de cada capítulo, que simula a voz do professor explicando em sala de aula. É importante salientar, aqui, que a Coleção se intitula Per se Illustrata. Isso significa que todo o estudo está pensado na ausência do professor. Margens, notas, imagens, explicações são uma tentativa de suprir uma presença necessária. Nesse volume, o conteúdo gramatical é abordado de forma simples, sem muitos adendos. O aprofundamento é feito nos capítulos subsequentes e na gramática.

O volume I da coleção do aluno gira em torno de textos não "autênticos", ou seja, que não circularam no mundo social e foram criados exclusivamente para fins didáticos. Está baseado numa contínua história de uma família romana, que é claramente construída com a finalidade de dar conta de um determinado conteúdo gramatical, ou seja, o texto é usado como pretexto para o ensino da gramática. Veja-se como exemplo o primeiro capítulo, cujo texto é formulado com o objetivo evidente de ensinar o verbo ESSE, o caso nominativo e o caso ablativo preposicionado (Figura 1 acima); singular e plural dos gêneros masculino, feminino e neutro, bem como os princípios básicos de concordância, como abaixo:

\footnotetext{
${ }^{3}$ O latim utilizado nas narrativas bíblicas é simples em suas construções: os vocábulos são bastante limitados, a estrutura está longe de se assemelhar a um texto de Cícero, por exemplo. Para isso, basta comparar o "In principio erat Verbum, et Verbum erat apud Deum, et Deus erat Verbum" (Jo 1,1) e o "Quo usque tandem abutere, Catilina, patientia nostra? quam diu etiam furor iste tuus nos eludet?" (Cícero, In Catilinam, I.1).
}

Revista Escrita

Rua Marquês de São Vicente, 225 Gávea/RJ CEP 22453-900 Brasil Ano 2012. Número 15. ISSN 1679-6888. escrita@puc-rio.br 


\begin{tabular}{|c|c|c|}
\hline $\begin{array}{l}\text { (numerus) singulâris: } 1 \text {; } \\
\text { plürălis: } \mathrm{Il}, \mathrm{III} . . \\
\text { fluvius magnus } \\
\text { fluvii magni } \\
-u s-i \\
\text { exemplum } \\
\text { exempla } \\
\text { insula magna } \\
\text { insulae magnae } \\
-a-a e\end{array}$ & \multicolumn{2}{|c|}{ 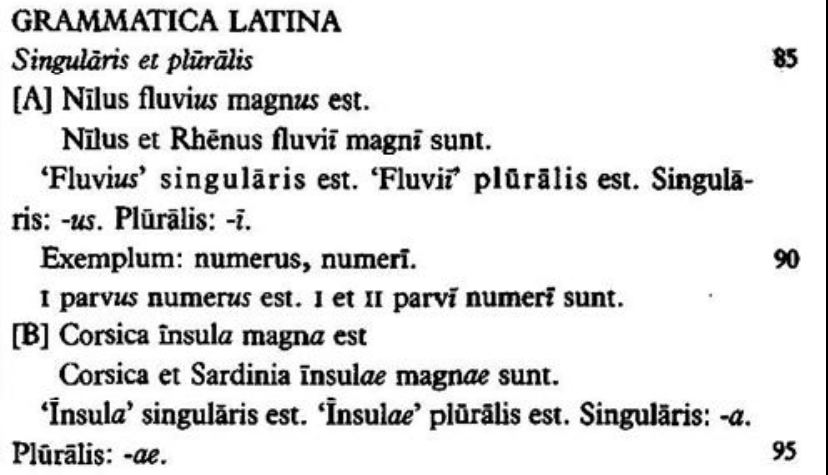 } \\
\hline $\begin{array}{l}\text { A littera La } \\
\text { prōvincia Rö } \\
\text { sunt. } \\
\text { [C] Brundisiu } \\
\text { Brundisiu } \\
\text { 'Oppidum' } \\
\text {-um. Plürälis: } \\
\text { Exempla: } \\
\text { Littera est }\end{array}$ & $\begin{array}{l}\text { ra, litterae; prōvincia, prôvinciae. } \\
\text { a est. A et B litterae Latīnae sunt. Gallia est } \\
\text { na. Gallia et Hispānia prōvinciae Römânae } \\
\text { oppidum magnum est. } \\
\text { et Sparta oppida magna sunt. } \\
\text { gulāris est. 'Oppida' plūrālis est. Singulāris: } \\
\text { - äbulum, vocābula; exemplum, exempla. } \\
\text { cābulum Latīnum, nôn Graecum. Littera et } \\
\text { ābula Graeca, sed Latīna sunt. }\end{array}$ & $\begin{array}{l}\text { oppidum magnum } \\
\text { oppida magna }\end{array}$ \\
\hline
\end{tabular}

Figura 2 - Conteúdo gramatical ao fim do capítulo (Ørberg, 1991, p.10-11)

Todos os capítulos são organizados em três seções, cujo nível de complexidade aumenta gradualmente. Cada página (cf. Figura 1 e 2) tem, na sua margem, explicações de vocábulos novos e de expressões, notas de uso gramatical e esclarecimento de sentido. Há, também, ilustrações autoexplicativas. Ao fim de cada capítulo, há uma sistematização do principal conteúdo gramatical abordado, conforme Figura 2.

Em seguida, passa-se a três atividades (cf. Figura 3), quase sempre dois exercícios de prática gramatical mecânica (RICHARDS, 2006) e uma de leitura pautada na decodificação do texto, o que Marcuschi (1996) denomina, ironicamente, de atividade de "copiação". Conforme afirma: "eles não são exercícios de compreensão, pois eles se preocupam apenas com aspectos formais ou então reduzem todo o trabalho de compreensão à identificação de informações objetivas e superficiais" (MARCUSCHI, 1996, p.64). 


\section{PENSVM C \\ Ubi est Rōma? \\ Estne Sparta in Italiā? \\ Ubi est Italia? \\ Ubi sunt Syria et Arabia? \\ Estne Aegyptus in Asiā? \\ Ubi sunt Sparta et Delphī? \\ Ubi est Brundisium? \\ Quid est Brundisium? \\ Num Crēta oppidurn est? \\ Estne Britannia insula parva? \\ Quid est Tiberis? \\ Quid est D? \\ Num $\Delta$ littera Latīna est? \\ Estne II magnus numerus?}

Figura 3 - Exercícios de compreensão do texto

No fragmento acima, as perguntas são de "copiação" sobre o capítulo Imperium Romanum, com sua primeira página reproduzida (Figura 1). Em todas elas o leitor unicamente realiza a tarefa de identificar a resposta e copiá-la, sem que se abarque outra habilidade ou estratégia de leitura que permita uma efetiva interação texto-leitor (MOITA LOPES, 1996; KLEIMAN, 2008).

No fim de cada capítulo, há um índice de vocábulos novos que aparecem no texto. É enfatizada a memorização de cada um desses vocábulos antes de passar à lição seguinte $^{4}$. Diz-se que, ao fim do curso básico, o aluno "possui" um vocabulário de mais de mil e quinhentas palavras, como se o processo de memorização garantisse, necessariamente, a aquisição da língua-alvo.

É importante observar que, ao confeccionar os textos, o autor não se limitou ao uso de um latim tão vulgar quanto se possa pensar. Obviamente, em um primeiro momento, encontramos um latim de fácil compreensão, mas aos poucos seu nível de dificuldade aumenta a ponto de imitar a fraseologia clássica. O conteúdo progride continuamente.

O primeiro volume é composto somente por textos adaptados, mas o segundo é uma rica seleta de textos clássicos (cf. Figura 4), com pequenos trechos adaptados para encadeamento das ideias. O original, quando apresentado, é colocado na íntegra:

\footnotetext{
${ }^{4}$ No guia de didática latina, essa questão é colocada explicitamente. No livro didático, a sua estrutura subentende essa memorização.

Revista Escrita

Rua Marquês de São Vicente, 225 Gávea/RJ CEP 22453-900 Brasil

Ano 2012. Número 15. ISSN 1679-6888.

escrita@puc-rio.br
} 


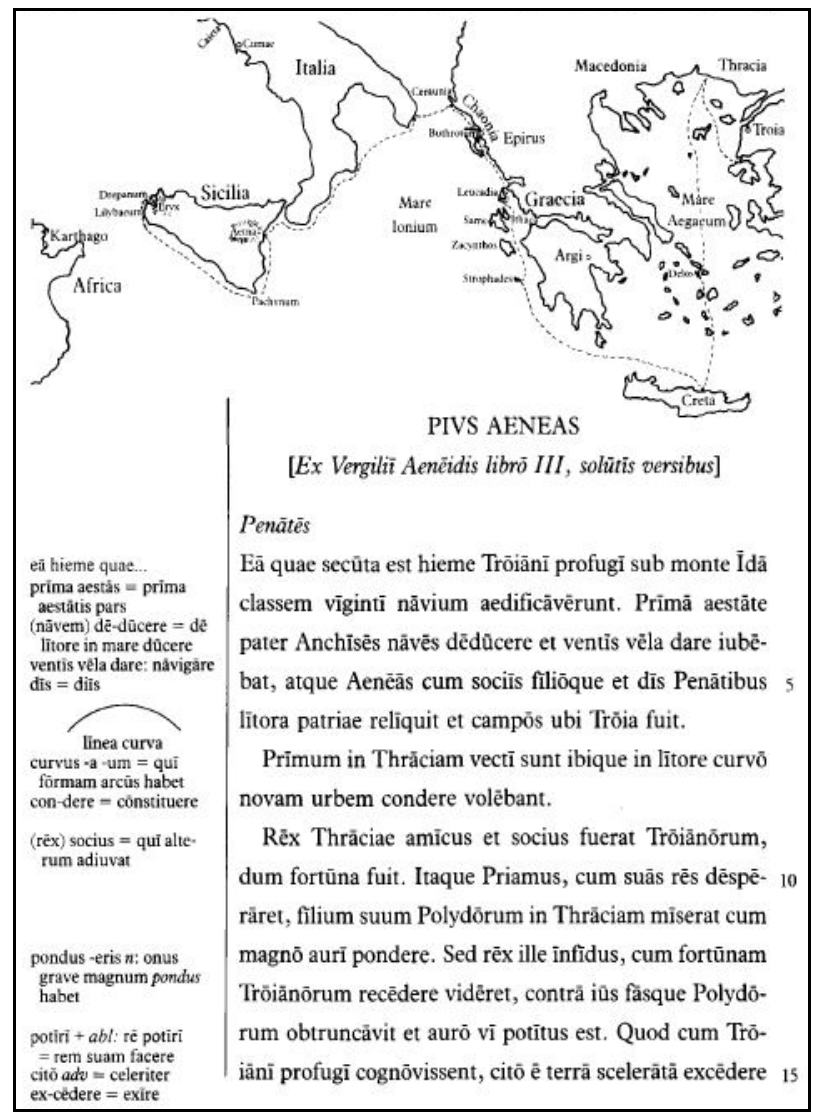

Figura 4 - Capítulo do Volume II: LLPSI - Roma Aeterna (Ørberg, 1990, p.10-11)

Nesse volume, não há mais explicações gramaticais, mas a estrutura dos exercícios continua semelhante à do anterior, qual seja, exercícios de prática gramatical mecânica e leitura pautada na decodificação.

Suplementos como obras de Vergílio, César, Plauto e outros também fazem parte do curso. Por ser per se illustratta, os volumes sempre seguem o mesmo estilo: há uma pretensão de que o conjunto "texto + diagramação + margens" baste-se per se. Todos têm o texto original e cadernos de exercícios para estes autores também estão disponíveis.

Lingua Latina Per se Illustrata, embora apresente uma roupagem mais atual em sua diagramação em relação a outros livros didáticos que já pudemos analisar, tem uma concepção de língua como um conjunto de estruturas. Sua concepção de ensino também se aproxima da behaviorista, com as sentenças organizadas de maneira progressiva e a base no estímulo-resposta-reforço.

Os demais volumes da coleção são listados abaixo. Como nos limitamos a analisar só o volume principal do curso básico, não nos preocuparemos em detalhar os outros volumes.

Revista Escrita 


\begin{tabular}{|c|c|}
\hline \multicolumn{2}{|c|}{ Curso avançado } \\
\cline { 1 - 1 } Aenēis & \\
\cline { 1 - 1 } Ars amātōria & \\
\cline { 1 - 1 } Catilīna & \\
\cline { 1 - 1 } Cēna Trimalchiōnis & \multirow{2}{*}{ Hans H. Ørberg } \\
\cline { 1 - 1 } $\begin{array}{c}\text { Enchīridion } \\
\text { discipulōrum II } \\
\text { (cap. XXXVI-LVI) }\end{array}$ & \\
\hline $\begin{array}{c}\text { Exercitia Latīna II } \\
\text { (cap. XXXVI-LVI) }\end{array}$ \\
\cline { 1 - 1 } Rōma aeterna \\
\cline { 1 - 1 } Būcolica carmina & \\
\hline
\end{tabular}

Na perspectiva do ensino tendo como eixo os gêneros, o texto não deve servir de pretexto para o ensino da gramática. Isso não acontece no livro didático analisado. $\mathrm{O}$ Gráfico 1 mostra a diversidade de gêneros presentes ao longo de todo o livro. Não há, de fato, uma ênfase na formação da competência leitora dos alunos, mas uma ênfase no próprio método em si mesmo que se denomina autoilustrativo: é prevista a utilização de textos artificiais para o ensino de um determinado conteúdo gramatical e se pauta em um texto didatizado narrativo ou descritivo, ocorrendo em $68,57 \%$ (24 ocorrências). A presença de outros gêneros discursivos resume-se a ocorrências em número de 8,57\% (3 ocorrências) de diálogos e seletas de poesia; uma pequena parcela de 2,86\% (1 ocorrência) incluindo o gênero bíblico e o gênero gramática; e 5,71\% (2 ocorrências) de fábulas didatizadas, cenas didatizadas e de carta do total dos 35 capítulos que compõem o primeiro volume da coleção.

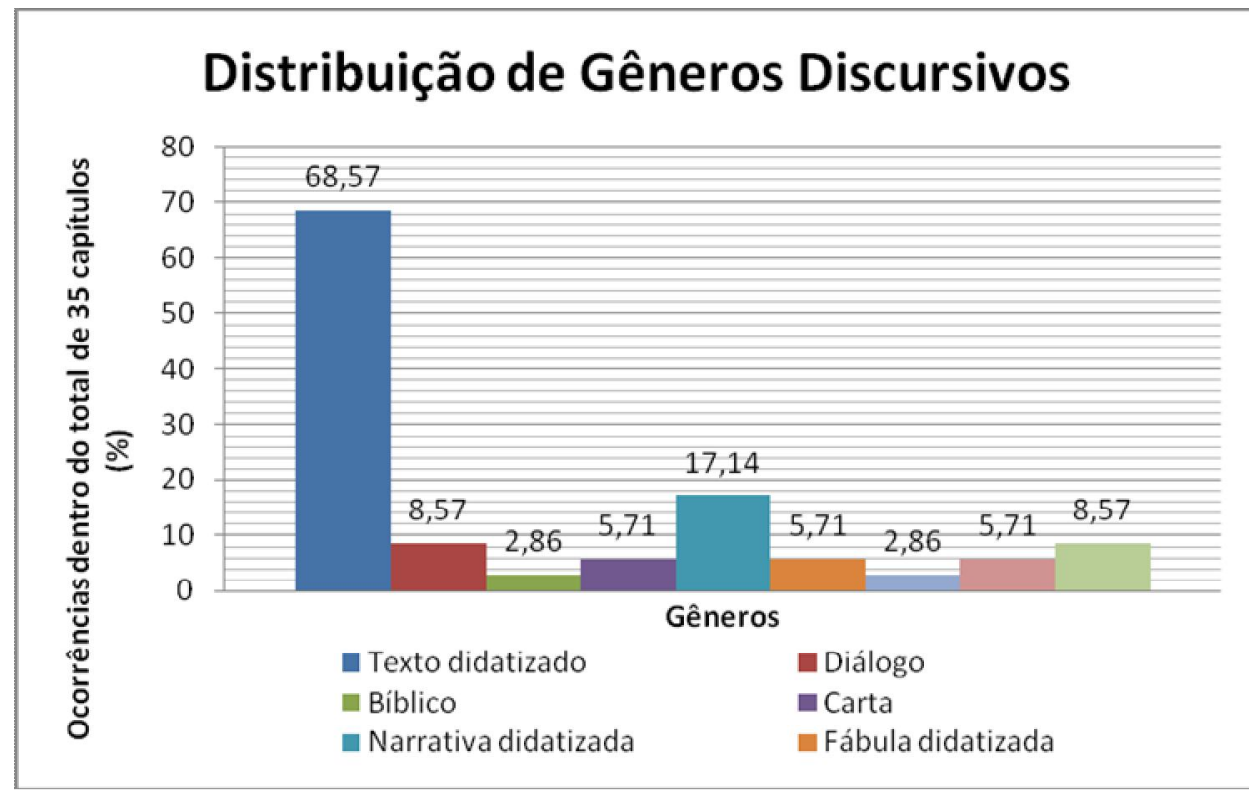

Gráfico 1 - Ocorrência de Gêneros Discursivos ao longo dos 35 capítulos do livro Revista Escrita

Rua Marquês de São Vicente, 225 Gávea/RJ CEP 22453-900 Brasil Ano 2012. Número 15. ISSN 1679-6888. escrita@puc-rio.br 
Pensamos, em uníssono com estudiosos como Geraldi (2006) e Rojo (2005; 2008), que a produção de texto e as práticas de leitura devem ser as norteadoras da prática docente. O texto é o ator principal na formação do aluno; não compêndios de gramática e exercícios mecanicistas, não traduções fora de contexto, sem situar o texto no seu momento de enunciação ou sem uma pré-leitura. A leitura de um texto, mesmo em língua materna, sem a devida ancoragem na enunciação já pode ser difícil; analisar um texto assim pode ser muito menos frutuoso. Dessa forma, perguntamo-nos: por que não abordar o ensino das letras clássicas de forma semelhante à que se propõe para a língua materna e as estrangeiras?

Moita Lopes (1996, p. 148-149) sistematiza os diversos conceitos de leitura como segue:

a) ascendente: a informação flui do texto para o leitor; processo perceptivo e de decodificação.

b) descendente: contribuição do leitor para o ato de ler; significado do texto na mente do leitor; movimento leitor-texto.

c) ascendente/descendente: processamento do texto nas duas direções; ato de ler visto como envolvedor de processos perceptivos e cognitivos; um modelo interacionista.

Defensor da proposta interacionista, o autor afirma que o significado "não está nem no texto, nem na mente do leitor; o significado torna-se possível através do processo de interação entre o leitor e o escritor, através do texto" (MOITA LOPES, 1996, p. 149). Dificuldade na compreensão escrita "parece indicar que as dificuldades na leitura podem ser explicadas não só por problemas quanto à decodificação do texto, como entendido tradicionalmente, mas também por dificuldades causadas pela falta de esquemas apropriados por parte do leitor" (MOITA LOPES, 1996, p. 149).

Justamente a partir desse ponto de articulação entre o ensino e o estudo da linguagem - continua Moita Lopes (1996, p. 150) - é que podemos identificar que o professor de Letras Clássicas normalmente "centra suas aulas em aspectos sistêmicos: morfológicos, sintáticos e léxico-semânticos", como é o caso do livro em questão. A causa torna-se patente: carência de esquemas (conhecimento prévio) por parte do aluno; esses seriam fundamentais para os aspectos interpretativos do texto.

A proposta de uma solução para a questão é bastante simples: a interação leitortexto. Diz o autor (MOITA LOPES, 1996, p. 151-152):

É por meio do relacionamento de conhecimentos sistêmicos com esquemáticos através de procedimentos interpretativos (por exemplo, a integração da formação nova com a já conhecida, a utilização da característica de predictabilidade da organização do discurso, a realização de inferências, a procura de laços coesivos no discurso etc.) que o leitor negocia o significado do texto com o escritor. [...] O aluno de LCs já está familiarizado com o ato de ler em sua LM e, por vezes, em uma ou mais LEs. Portanto, o que ele tem a fazer é aprender a utilizar os procedimentos interpretativos, que já são do seu conhecimento, ao aprender a ler em uma LC. Todavia, devido à falta de conhecimento sistêmico e esquemático por parte do aluno, esses procedimentos não podem ser ativados, por assim dizer, pelo leitor-aprendiz. O professor tem, então, de facilitar a

Revista Escrita

Rua Marquês de São Vicente, 225 Gávea/RJ CEP 22453-900 Brasil

Ano 2012. Número 15. ISSN 1679-6888.

escrita@puc-rio.br 
utilização desses procedimentos interpretativos através de artifícios pedagógicos adequados.

Investir nessa compreensão do texto conforme explica o autor seria mais proveitoso e mais favorável à formação de leitores proficientes. Não obstante, justifica a nossa posição em relação ao considerar as Letras Clássicas como mortas (MOITA LOPES, 1996, p. 152-153):

Colocando-se o foco principal do curso no ensino de conhecimento sistêmico. É natural que, por causa das dificuldades da sintaxe, da morfologia e do léxico dessas línguas, o professor tenha geralmente centrado suas aulas nesses aspectos. O que acontece, porém, é que o professor nesse caso parece estar operando na sala de aula a partir de uma visão de leitura como decodificação em que o significado é visto como estando contido nos elementos sistêmicos estudados no texto a ser lido. Esta visão, como foi dito acima, parece estar equivocada, pois não reflete o que ocorre no ato de compreensão escrita, conforme as pesquisas têm demonstrado (cf. Rumelhart, 1977).

[...] Esta concepção de leitura parece ser especialmente prejudicial para o ensino de LCs, devido a reforçar o seu caráter de língua morta, pois reflete uma visão nãocomunicativa da natureza da linguagem em que a contribuição dos participantes na construção do significado, o leitor e o escritor, no ato da compreensão não é levada em consideração.

Esta visão proporciona uma palavra de ordem: "recuperação da natureza comunicativa da linguagem" (MOITA LOPES, 1996, p. 153). Como? Colocando "ênfase no pré-conhecimento do leitor-aprendiz, ou seja, na sua contribuição para o ato comunicativo da leitura. (...) Ensinar o leitor-aprendiz a ativar e utilizar o conhecimento esquemático necessário para a compreensão de um determinado texto" (MOITA LOPES, 1996, p. 153).

É preciso criar expectativas no leitor-aprendiz por meio da indução da área de conteúdo esquemático, que serão confirmadas ou não em sua leitura. Compreensão do texto é feita através de recursos pedagógicos, ativando o conhecimento do aluno. É preciso, portanto, utilizar a organização retórica do texto como fornecedora de pistas

para seu acesso ao significado. É preciso que o leitor-aprendiz se familiarize com os marcadores do discurso (conectores, itens lexicais etc.) que indicam a organização da informação no discurso (MOITA LOPES, 1996, p. 154-155).

\section{Palavras finais}

Tendo em vista todas as reflexões presentes neste trabalho, terminamos com algumas indagações. Estariam os estudos sobre o ensino de letras clássicas estagnados no tempo? Estaríamos cerca de 100 anos atrasados em relação ao ensino de línguas, tanto materna quanto estrangeiras modernas? Estaríamos adotando uma postura de verdadeiros educadores quando não refletimos sobre o ensino a que nos prestamos hoje? São perguntas para as quais que gostaríamos de ter respostas precisas, que viessem primordialmente de um desenvolvimento de pesquisas sobre o ensino das letras

Revista Escrita

Rua Marquês de São Vicente, 225 Gávea/RJ CEP 22453-900 Brasil

Ano 2012. Número 15. ISSN 1679-6888.

escrita@puc-rio.br 
clássicas, não apenas de sua língua e literatura, tão farta e proficuamente estudadas.

Pensar gêneros discursivos no ensino de letras clássicas é uma abordagem possível e que dialoga com o mundo social e com as demais subáreas do âmbito dos estudos aplicados da linguagem. Acreditamos que, com isso, o estudante seria partícipe, e não mero espectador do monumento que é a cultura clássica. Alea iacta est.

\section{Referências Bibliográficas}

Textos teóricos:

BAKHTIN, M. Estética da criação verbal. Trad. Paulo Bezerra. São Paulo: Martins Fontes, 2006.

BENTES, A. C. Gênero e ensino: algumas reflexões sobre a produção de materiais didáticos para a educação de jovens e adultos. In: KARWOSKI, A. M.; GAYDECZKA, B.; BRITO, K. S. (org.). Gêneros textuais: Reflexões e Ensino. Rio de Janeiro: Nova Fronteira, 2008.

BONINI, A.; MOTTA-ROTH, D. (org.). Gêneros: teorias, métodos, debates. São Paulo: Parábola Editorial, 2005.

. Gêneros de discurso/texto como objeto de ensino de línguas: um retorno ao trivium? In:

SIGNORINI, I. (org.). [Re]discutir texto, gênero e discurso. São Paulo: Parábola Editorial, 2008 .

COUTINHO, I. L. Gramática Histórica. Rio de Janeiro: Livraria Acadêmica, 1970.

FREITAS, L. M. A.; BARRETO, T.A. Práctica de la Enseñanza de Lengua Española I. Rio de Janeiro: CCAA Editora, 2008.

GERALDI, J. W (org.). O texto na sala de aula. São Paulo: Ática, 2006.

KLEIMAN, A. Oficina de Leitura. Campinas: Mercado de Letras, 2008.

MAINGUENEAU, D. Análise de textos de comunicação. São Paulo: Cortez, 2002.

1997.

. Novas tendências em análise de discurso. Tradução de F. Indursky Campinas: Pontes,

MARCUSCHI, L. A. Exercícios de compreensão ou copiação nos manuais de ensino de língua? In: Revista Em aberto. Brasília, ano 16, nº 69, jan./mar., 1996.

MOITA LOPES, L.P. Oficina de Linguística Aplicada. Campinas: Mercado das Letras, 1996.

MONTEIL, P. Elementos de Fonética y Morfología del Latín. Tradución, introducción, notas suplementarias y actualización de La bibliografia de Concepción F. Martínez. Sevilla, 2003.

RICHARDS, J.C. O ensino comunicativo de línguas estrangeiras. São Paulo: SBS, 2006

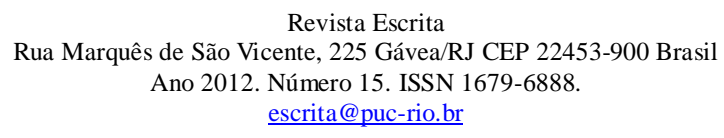


; RODGERS, T. Enfoques y métodos en la enseñanza de idiomas. Madrid: Cambridge University Press, 1998

ROJO, R. Gêneros do discurso e gêneros textuais: questões teóricas e aplicadas. In: MEURER, J. L.;

VOLOSHINOV, V.N. El marxismo y la filosofia del lenguaje. Tradução de T. Bubnova. Buenos Aires: Godot, 2009.

WILliAMS, E. B. Do Latim ao Poirtuguês: fonologia e morfologia históricas da lingual portuguesa. Trad. Antônio Houaiss. $2^{\mathrm{a}}$ Ed. Rio de Janeiro, Tempo Brasileiro; Brasília, INL, 1973.

ØRBERG, H. Lingua Latina Per Se Ilustratta (coleção). Montella: Edizione Accademia Vivarium Novum, 2007. 